\title{
Hypoglycemia in everyday life after gastric bypass and duodenal switch
}

\author{
Niclas Abrahamsson ', Britt Edén Engström' ${ }^{1}$, Magnus Sundbom ${ }^{2}$ \\ and $\mathbf{F}$ Anders Karlsson ${ }^{1}$ \\ Departments of ${ }^{1}$ Medical Sciences and ${ }^{2}$ Surgical Sciences, Uppsala University Hospital, S-751 85 Uppsala, Sweden
}

\author{
Correspondence \\ should be addressed \\ to N Abrahamsson \\ Email \\ niclas.abrahamsson@ \\ medsci.uu.se
}

\begin{abstract}
Design: Gastric bypass (GBP) and duodenal switch (DS) in morbid obesity are accompanied by marked metabolic improvements, particularly in glucose control. In recent years, episodes of severe late postprandial hypoglycemia have been increasingly described in GBP patients; data in DS patients are scarce. We recruited three groups of subjects; 15 GBP, 15 DS, and 15 non-operated overweight controls to examine to what extent hypoglycemia occurs in daily life.

Methods: Continuous glucose monitoring (CGM) was used during 3 days of normal activity. The glycemic variability was measured by mean amplitude of glycemic excursion and continuous overall net glycemic action. Fasting blood samples were drawn, and the patients kept a food and symptom log throughout the study.

Results: The GBP group displayed highly variable CGM curves, and $2.9 \%$ of their time was spent in hypoglycemia $(<3.3 \mathrm{mmol} / \mathrm{l}$, or $60 \mathrm{mg} / \mathrm{dl})$. The DS group had twice as much time in hypoglycemia $(5.9 \%)$ and displayed CGM curves with little variation as well as lower HbA1c levels $(29.3 \mathrm{vs} 35.9 \mathrm{mmol} / \mathrm{mol}, P<0.05)$. Out of a total of 72 hypoglycemic episodes registered over the 3-day period, $70(97 \%)$ occurred in the postprandial state and only about one-fifth of the hypoglycemic episodes in the GBP and DS groups were accompanied by symptoms. No hypoglycemias were seen in controls during the 3-day period.

Conclusion: Both types of bariatric surgery induce marked, but different, changes in glucose balance accompanied by frequent, but mainly unnoticed, hypoglycemic episodes. The impact and mechanism of hypoglycemic unawareness after weight-reduction surgery deserves to be clarified.
\end{abstract}

\section{Introduction}

Obesity is a global and continuously growing health problem, for which medical and diet treatment is often not effective enough. Thus, the number of bariatric operations is steadily on the rise, with Roux-en-Y gastric bypass (GBP) surgery being the most common and duodenal switch (DS) being reserved for the most extreme cases (1). These procedures have been shown to be superior to gastric banding and sleeve gastrectomy when it comes to resolving comorbidities, such as diabetes, hypertension, hyperlipidemia, and sleep apnea, and also when considering degree of weight loss (1). Furthermore, DS achieved superior weight loss as compared to GBP $(80 \%$ vs $51 \%$ of excess BMI loss) in super-obese patients (BMI $>50)$ when they were compared in a randomized trial (2). Postoperatively, both GBP and DS patients are asked to alter food intake to smaller, more frequent meals that contain less sugar and more protein. The post-GBP anatomy implies a fast passage of nutrients to the small intestine (proximal jejunum), which stimulates $\mathrm{L}$ cells to an enhanced incretin response. This differs from the postDS situation, wherein ingested food is passed directly into the ileum and fat-soluble nutrients are absorbed only after chyme has been mixed with bile in the most distal part of the ileum. Thus, one major difference between the two

Published by Bioscientifica Ltd. 
methods is the absorptive capability of the small intestine, which is greater in the post-GBP state, although it is diminished as compared to normal anatomy.

Postoperative complications include dumping syndrome and vitamin deficiencies, but problems with postprandial GBP-related hypoglycemia, which occurs 1-3 $\mathrm{h}$ after meals, are more troublesome. Symptoms are, however, often diffuse (3), which thus delays diagnosis until 1-3 years after surgery (4). The prevalence of postprandial hypoglycemia after bariatric surgery is uncertain. In 2010, Marsk et al. (5) used the Swedish National Patient Registry, which contains data on 50 million discharges, to extract an absolute risk of $0.2 \%$ for a postoperative bariatric patient to require hospital care because of postprandial hypoglycemia, as compared to $0.04 \%$ in the general population. There was no report on hypoglycemia prevalence after DS; the absolute number of DS-operated patients in the register is low.

The genesis of postprandial hypoglycemia after bariatric surgery is largely unknown; however, it is noteworthy that neither the reversal of $\operatorname{GBP}(6,7)$ nor partial pancreatectomy is uniformly successful $(6,8)$. Rather, it seems that the change in anatomy post-surgery that leads to the rapid presentation of food to the more distal small intestine and a rapid rise and fall in blood glucose accompanied by altered hormonal profiles postprandially is responsible for the hypoglycemia problem. Attention has been mostly paid to the tenfold rise in glucagon-like peptide-1 (GLP-1) post-GBP and the subsequent steep rise in insulin and quick fall in glucose. Reports of the number of islets in the post-GBP patient's pancreas are conflicting $(6,8,9)$, and no increase in the number of GLP-1 receptors has been observed (10). The rise in GLP-1 is higher in post-GBP patients with hyperinsulinemic hypoglycemia with neuroglucopenia $(4,11)$, and experimental and short time blockade of the GLP-1 receptor markedly decreases insulin secretion and corrects postprandial hypoglycemia (12). In recent years, emerging evidence in patients with diabetes treated with insulin has suggested that hypoglycemia can have detrimental effects. Patients who have a significant number of hypoglycemic episodes are associated with higher all-cause mortality (13), risk of dementia (14), lower quality of life (15), and higher risk of motor vehicle accidents (16). It has been speculated that postprandial hypoglycemia might be linked to an increased risk of accidents post-bariatric surgery (17).

Continuous glucose monitoring (CGM) has been used to some extent in bariatric patients. Ritz et al. (18) examined eight post-GBP patients with dumping syndrome to categorize their glucose curves. When they were treated with acarbose and diet modification, the time to maximum interstitial glucose (IG) was increased and so was the subsequent decrease in IG. The absolute IG values were reduced from 2.5 to $0.18 \%$, and the time with IG below $60 \mathrm{mg} / \mathrm{dl}(3.3 \mathrm{mmol} / \mathrm{l})$ also decreased. Hanaire et al. (19) compared three groups - post-GBP, diabetic, and healthy controls - of ten patients each with CGM. Post-surgery patients had shorter timeto-postprandial-peak-glucose levels and also higher peak levels per se. Hypoglycemia, which is defined as $<60 \mathrm{mg} / \mathrm{dl}$ $(<3.3 \mathrm{mmol} / \mathrm{l})$ glucose, was found $2 \%$ of the time. Furthermore, when examined with CGM, nine of the ten post-GBP patients with a history of reporting neuroglycopenic symptoms and three of the six post-GBP patients without such symptoms had hypoglycemic episodes, which are defined as $<70 \mathrm{mg} / \mathrm{dl}(3.9 \mathrm{mmol} / \mathrm{l})$ IG. Time with hypoglycemia ( $<60 \mathrm{mg} / \mathrm{dl}$, or $<3.3 \mathrm{mmol} / \mathrm{l}$ glucose) was $2.6 \%$ in the symptomatic group and $1.6 \%$ in the non-symptomatic group (20).

In DS patients, there has not, to our knowledge, been any study of daily glucose values using CGM. However, in line with the altered glucose absorption routes postsurgery, it has been noted that the peak levels of glucose and insulin during meal tests are lower in DS patients (21), and they are also lower in DS patients as compared to post-GBP or post-sleeve gastrectomy surgery patients (22). Furthermore, patients who have undergone biliopancreatic diversion, a procedure performed in DS, exhibit insulin supersensitivity (23)

There is no established treatment for late postprandial hypoglycemia. Several treatments have been proposed in the literature; these involve acarbose $(24,25)$, calcium channel antagonists (nifedipine and verapamil) (26), the somatostatin analogues octreotide (27) and pasireotide (28), the $\beta$-cell inhibitor diazoxide (29), and finally and ultimately, partial pancreatectomy (30). Glucagon has been tried as infusion but has not been proven to be useful perhaps because of its concomitantly high levels of insulin (31). We have recently reported successful treatment with GLP-1 analogues (32). In the clinical setting, patients with postprandial hypoglycemic episodes after bariatric surgery are becoming more frequent, which is in line with an increase in the number of patients being operated. Because the extent of this problem is unknown, we used CGM to investigate the everyday glycemic variation, frequency of hypoglycemic episodes and their relation to food intake, and hypoglycemic symptoms after GBP and DS, and we compared the results to non-diabetic BMI-matched controls. 


\section{Patients and methods}

\section{Patients}

Three groups of patients were studied: 15 patients post-GBP surgery, 15 patients post-DS surgery, and 15 non-diabetic obese BMI-matched controls. The 30 postoperative patients were consecutively recruited at our outpatient clinic, and the 15 controls were recruited via an advertisement in a local newspaper. The GBP patients were investigated a median 1.5 years post-surgery and the DS patients 2.0 years post-surgery. GBP patients had a $70 \mathrm{~cm}$ Roux limb connected to a small proximal gastric pouch and a $30 \mathrm{~cm}$ bileopancreatic limb. In DS, a gastric sleeve was connected to a $250 \mathrm{~cm}$ alimentary limb that consisted of the distal part of the ileum. The remaining small bowel, the bileopancreatic limb, which consists of the jejunum, was thus excluded from the passage of food. After connecting the distal part of the bileopancreatic limb to the last $100 \mathrm{~cm}$ of the alimentary limb, the uptake of fat-soluble nutrients becomes possible in this short part of the small bowel.

\section{CGM and hypoglycemia}

For the continuous measuring of IG levels (IG measured every $10 \mathrm{~s}$ and mean glucose value given every $5 \mathrm{~min}$ ), Medtronic Minimed IPRO-2 (Minneapolis, MN, USA) was used. The CGM device was inserted by the study nurse according to instructions from the manufacturer, and patients and controls wore the CGM device for at least 3 days. In the event that the CGM device was worn for more than 3 days for practical reasons, only the data for the first 3 days was used. For calibration with capillary glucose, the Bayer CONTOUR (Leverkusen, Germany) glucose meter was used. Patients measured, according to instructions from the manufacturer, capillary glucose at four random times (maximum $12 \mathrm{~h}$ between measurements) daily for calibration purposes. All measurements were uploaded to the Carelink Software program (Medtronic) and then exported to Microsoft Excel.

A hypoglycemic episode was defined as postprandial if it occurred within $4 \mathrm{~h}$ of a meal; otherwise, it was considered fasting (33). A symptomatic hypoglycemia was defined as an episode on the CGM curve accompanied with any of the accepted symptoms of hypoglycemia, including autonomic and/or neuroglycopenic symptoms such as (autonomic) palpitations, hunger, sweating, tremors, weakness, and (neuroglycopenic) anxiety, irritability, personality change, ataxia, confusion, seizures, and a loss of consciousness $(3,34)$.

\section{Food diary}

Patients were instructed to live and eat normally and to keep a food diary in which they recorded the times of meals and the types and amounts of food consumed. If symptoms of hypoglycemia (as defined in the 'Introduction' section) occurred, they were reported to the investigator at the end of the 3-day CGM period. Because post-bariatric surgery meals are significantly smaller, a portion that consisted of at least $125 \mathrm{kcal}$ was defined as a meal.

\section{Biochemical measurements}

Fasting blood samples were drawn in the morning and analyzed at the Department of Clinical Chemistry at the University Hospital, Uppsala. The samples were drawn before the start of CGM to classify the basic metabolic characteristics of the patients. The design of the study did not allow sampling in connection with actual hypoglycemias. The laboratory is certified by a Swedish government authority (Swedac). If they were not analyzed immediately, samples were frozen at $-70^{\circ} \mathrm{C}$. Frozen samples from each study subject were thawed and analyzed in a single run for each analysis. The methods used were for glucagon (RIA (Millipore, Billerica, MA, USA)), growth hormone (GH; automated analysis Immulite XP), cortisol (automated analysis Cobas E (Roche)), and the metabolic hormones insulin (automated analysis Cobas E), leptin (RIA), and adiponectin (RIA). The metabolic markers 3- $\beta$ hydroxybutyrate (enzymatic spectrophotometric method) and free fatty acids (enzymatic method) were analyzed at the Laboratory of Karolinska Universitetssjukhuset, Stockholm, Sweden. HOMA-IR was calculated as follows: (fasting samples of insulin $\times$ glucose)/22.5 (35).

\section{Statistical analysis}

All statistical calculations were performed in Statistica (Statsoft Inc., Tulsa, OK, USA). Shapiro-Wilk's tests were performed for control of normality, and data were compared by one-way ANOVA to test for difference. If significant differences were detected, we further analyzed between groups by Student's $t$-test or, when appropriate (in cases of non-normality), by Mann-Whitney's $U$ test (Wilcoxon's rank sum test). A $P$ value of $<0.05$ was considered significant. The continuous overall net glycemic action (CONGA) and mean amplitude of glycemic excursion (MAGE) values were calculated by the EasyGV version 9.0 (Nathan R Hill, University of Oxford, Oxford, UK). 


\section{Glycemic variability measurements}

There are a wide variety of measurements of glycemic variability, but we chose to use the MAGE because of its widespread use and the CONGA because it is considered to be the most specific method available for analyzing CGM patterns $(36,37)$. The MAGE calculates the average size of fluctuations between adjacent peaks and nadirs in glucose levels, with peaks and nadirs being defined as at least \pm 1 s.D. from mean glucose (38). To further analyze the complex variability of the CGM curves, the CONGA method $(36,37)$ was used. The CONGA measurement is defined as the s.D. of the differences between the glucose values during the day (36).

\section{Ethics}

The Ethics Committee of Uppsala University, Sweden, approved the present study (Dnr 2011/063). Patients provided signed informed consent, and the study was conducted according to the Helsinki Declaration.

\section{Results}

\section{Patient characteristics}

Baseline characteristics of the three groups are demonstrated in Table 1 . The GBP group included 12 women with a median age of 46 (36-63) years, a median BMI of 29 (26-38) $\mathrm{kg} / \mathrm{m}^{2}$, and median of $1.5(1.0-2.0)$ years since surgery, whereas the 15 post-DS surgery group included seven women with a mean age of 42 (24-63), a median BMI of $32(26-38) \mathrm{kg} / \mathrm{m}^{2}$, and a median of $2.0(1.1-7.0)$ years since operation. The 15 non-diabetic obese BMImatched control group included 12 women with a mean age of 53 (25-74) years and a mean BMI of 30 (28-35) $\mathrm{kg} / \mathrm{m}^{2}$. As in clinical practice, the female dominance was larger in the GBP group than it was in the DS group, because this procedure is predominantly performed in super-obese patients. Control patients were slightly older, but there were no differences in present BMI. The postsurgery weight loss was significantly different, which reflected the different surgeries; the GBP group had a median loss of 13 BMI units, and the DS group had lost 23 BMI units. No patient had medicated with any antidiabetic/glucose-balance-modifying drugs. One of the DS patients (case no. 26) suffered from partial cortisol deficiency after pituitary surgery for a pituitary adenoma that had occurred 5 years before the study and was medicating with $10 \mathrm{mg}$ hydrocortisone per day as
Table 1 Participants' characteristics by surgical procedure and control. $n=15 /$ group. Medians (range).

\begin{tabular}{|c|c|c|c|}
\hline & GBP & DS & Control \\
\hline Age (years) & $46(36-63)$ & $42(24-63)$ & $53(25-74)$ \\
\hline $\begin{array}{l}\text { Gender (female/ } \\
\text { male) }\end{array}$ & $12 / 3$ & $7 / 8$ & $12 / 3$ \\
\hline Years since surgery & $1.5(1.0-2.0)$ & $2.0(1.1-7)$ & NA \\
\hline BMI $\left(\mathrm{kg} / \mathrm{m}^{2}\right)$ & $29(26-38)$ & $32(26-38)$ & $30(28-35)$ \\
\hline $\begin{array}{l}\text { BMI loss (units } \\
\mathrm{kg} / \mathrm{m}^{2} \text { ) }\end{array}$ & $13(7-17)$ & $23(9-27)$ & NA \\
\hline Systolic BP & $115(110-150)$ & $120(100-140)$ & $125(110-150)$ \\
\hline Diastolic BP & $80(65-100)$ & $70(60-90)$ & $80(75-95)$ \\
\hline Pulse rate & $66(60-81)$ & $64(56-76)$ & $80(63-76)$ \\
\hline
\end{tabular}

replacement therapy. When calculating the results without patient no. 26 's data, the results did not change.

\section{Metabolic parameters at baseline}

Laboratory results are demonstrated in Table 2. The two post-surgery groups had significantly lower levels of glucose, HbA1c, blood lipids, insulin, HOMA-IR, and leptin as compared to controls. Furthermore, the DS group had higher adiponectin levels as compared to both controls and the GBP group. There were no significant differences in fasting concentrations of glucagon or cortisol, but there were higher levels of GH in the DS group as compared to the controls. The fasting morning concentrations of 3- $\beta$ hydroxybutyrate were equal among the groups. The levels of free fatty acids were within the normal range for all groups, although the DS group had significantly lower levels than the controls did.

\section{Glucose homeostasis: CGM}

The GBP group had a considerably high variability of their glucose curves, whereas the DS group had a considerably low variability when they were compared with both the MAGE and the CONGA variability methods (Fig. 1). Examples of three typical CGM curves for each group can be seen in Fig. 2. The GBP group had a high mean MAGE value of 3.2 , as compared to the controls' mean value of 2.4, and the DS group's low mean value of 1.5 (Fig. 2). The GBP group also had a high CONGA score, whereas the scores of the control and DS groups were lower (2.1 vs 0.7 and 0.5 respectively). Both post-surgery groups had a high number of measurements of $<60 \mathrm{mg} / \mathrm{dl}$ $(<3.3 \mathrm{mmol} / \mathrm{l})$ glucose and long times in a hypoglycemic state (GBP: $42 \mathrm{~min} / 24 \mathrm{~h}$ ( $2.9 \%$ of the time) and DS:

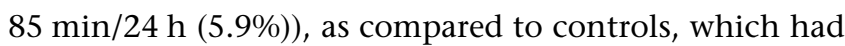


Table 2 Metabolic parameters, inflammatory markers, and counter-regulatory hormones measured at baseline before the start of CGM 1.5 (1.0-2.0) years after RYGB and 2.0 (1.1-7.0) years after DS. Means (s.E.M.); range given for glucose and $\mathrm{HbA} 1 \mathrm{c}$.

\begin{tabular}{|c|c|}
\hline & $\mathbf{G B P}(n=15)$ \\
\hline $\mathrm{CRP}(\mathrm{mg} / \mathrm{l})$ & $3.6( \pm 1.6)$ \\
\hline Albumin $(g / l)$ & $39.1( \pm 0.6)$ \\
\hline Cholesterol (mmol/l) & $5.2( \pm 0.2)^{\dagger}$ \\
\hline HDL cholesterol (mmol/l) & $1.5( \pm 0.07)^{\dagger}$ \\
\hline LDL cholesterol (mmol/l) & $3.2( \pm 0.2)^{\dagger}$ \\
\hline Triglycerides (mmol/l) & $1.3( \pm 0.2)$ \\
\hline $\begin{array}{l}\text { Glucose }(\mathrm{mmol} / \mathrm{l}) \\
(\mathrm{mg} / \mathrm{dl})\end{array}$ & $\begin{array}{l}5.3( \pm 0.2 ; 4.1-6.4) \\
95(74-115)^{*,+}\end{array}$ \\
\hline $\mathrm{HbA} 1 \mathrm{c}(\mathrm{mmol} / \mathrm{mol})$ & $36( \pm 0.9 ; 29-43)$ \\
\hline (NGSP\%) & $5.4(4.8-6.1)^{\dagger}$ \\
\hline HOMA-IR & $2.2( \pm 0.5)^{\dagger}$ \\
\hline Insulin (mE/l) & $11.1( \pm 2.6)^{\dagger}$ \\
\hline fP-Glukagon (ng/l) & $66.9( \pm 6.1)$ \\
\hline Cortisol (nmol/l) & $348( \pm 28.2)$ \\
\hline Growth hormone $(\mu \mathrm{g} / \mathrm{l})$ & $1.9( \pm 0.6)$ \\
\hline 3- $\beta$-hydroxybutyrate $(\mathrm{mmol} / \mathrm{l})$ & $0.06( \pm 0.01)$ \\
\hline Free fatty acids (mmol/l) & $0.48( \pm 0.06)$ \\
\hline P-leptin $(\mu \mathrm{g} / \mathrm{l})$ & $14.5( \pm 2.1)^{*}$ \\
\hline P-adiponectin (mg/l) & $13.5( \pm 1.4)$ \\
\hline
\end{tabular}

\begin{tabular}{c}
\hline DS $(n=15)$ \\
\hline $1.3( \pm 0.4)$ \\
$38.0( \pm 1.4)$ \\
$3.6( \pm 0.1)^{\star}$ \\
$1.1( \pm 0.07)^{*}$ \\
$1.9( \pm 0.14)^{*}$ \\
$1.0( \pm 0.1)$ \\
$4.6( \pm 0.1 ; 3.8-5.7)$ \\
$83(68-103)^{\star}$ \\
$29( \pm 1.3 ; 16-34)$ \\
$4.8(3.8-5.3)^{*}$ \\
$1.0( \pm 0.2)^{\star}$ \\
$5.0( \pm 0.8)^{*}$ \\
$77.5( \pm 5.7)$ \\
$295( \pm 31.8)$ \\
$3.1( \pm 0.9)^{\star}$ \\
$0.06( \pm 0.01)$ \\
$0.43( \pm 0.04)^{*}$ \\
$8.7( \pm 2.1)^{\star}$ \\
$20.1( \pm 3.8)^{*}$ \\
\end{tabular}

\begin{tabular}{c}
\hline Control $(n=15)$ \\
\hline $2.8( \pm 0.7)$ \\
$38.5( \pm 0.7)$ \\
$5.3( \pm 0.2)$ \\
$1.5( \pm 0.08)$ \\
$3.0( \pm 0.4)$ \\
$1.6( \pm 0.3)$ \\
$5.9( \pm 0.2 ; 4.9-7.1)$ \\
$106(88-128)$ \\
$38( \pm 1.3 ; 30-47)$ \\
$5.6(4.9-6.5)$ \\
$3.2( \pm 0.6)$ \\
$12.3( \pm 2.2)$ \\
$77.5( \pm 6.8)$ \\
$362( \pm 25)$ \\
$0.7( \pm 0.2)$ \\
$0.08( \pm 0.02)$ \\
$0.55( \pm 0.03)$ \\
$28.9( \pm 3.6)$ \\
$11.4( \pm 1.5)$ \\
\end{tabular}

$* P<0.05$ vs controls and ${ }^{\dagger} P<0.05$ for GBP vs DS.

no such values at all. When examining glucose levels of $<2.8 \mathrm{mmol} / \mathrm{l}(<50 \mathrm{mg} / \mathrm{dl})$, the GBP group had $21 \mathrm{~min} /$ $24 \mathrm{~h}(1.5 \%)$, and the DS group had $39 \mathrm{~min} / 24 \mathrm{~h}(2.7 \%)$. The absolute majority of hypoglycemic episodes were 30 min to $4 \mathrm{~h}$ postprandial, with $0.6 / 24 \mathrm{~h}$ in the post-GBP group and 1.0/24 $\mathrm{h}$ in the post-DS group (Table 3). Out of a total of 72 hypoglycemic episodes registered over the 3-day period, 70 (97\%) occurred in the postprandial state (Table 4). Thus, fasting hypoglycemia was scarce, with only one DS and one GBP patient exhibiting one single episode each (GBP patient: $105 \mathrm{~min}$ and DS patient: $120 \mathrm{~min})$. Symptoms without measured hypoglycemia were also very rare; they were reported by only one GBP patient (three episodes during the 3 days of recording).

When comparing the baseline laboratory parameters determined at the start of CGM between the subjects who subsequently presented with and without hypoglycemic episodes during the CGM in the two post-surgery groups, no significant differences were found, except for fasting glucose level in post-GBP subjects with and without hypoglycemia $(4.5 \mathrm{mmol} / \mathrm{l}(81 \mathrm{mg} / \mathrm{dl})$ and $5.2 \mathrm{mmol} / \mathrm{l}$ $(93.6 \mathrm{mg} / \mathrm{dl})$ glucose respectively, $P=0.03)$.

The DS group had significantly lower mean IG levels during the CGM than the other groups did $(4.8 \mathrm{mmol} / \mathrm{l}$ $(86.4 \mathrm{mg} / \mathrm{dl})$ vs $5.9 \mathrm{mmol} / \mathrm{l}(106.2 \mathrm{mg} / \mathrm{dl})$ and $6.2 \mathrm{mmol} / \mathrm{l}$ $(111.6 \mathrm{mg} / \mathrm{dl})$ for the GBP and control groups respectively). The difference between fasting glucose and nadir glucose (during CGM), $\Delta$ glucose, was not significant between the three groups. The DS group exhibited the lowest $\mathrm{HbA1c}, 29.3 \mathrm{mmol} / \mathrm{mol}(4.8 \%)$, as compared to $35.9 \mathrm{mmol} / \mathrm{mol}(5.4 \%)$ and $37.9 \mathrm{mmol} / \mathrm{mol}(5.6 \%)$ for the GBP and control groups respectively.

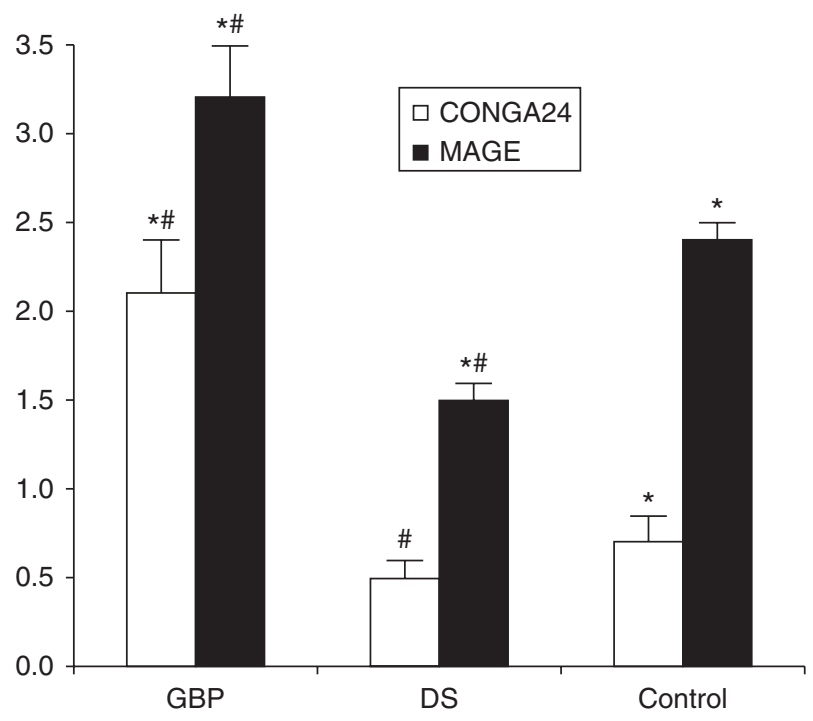

Figure 1

Glucose variability scores, mean values per group. MAGE, mean amplitude of glycemic excursion; CONGA, continuous overall net glycemic action. ${ }^{*} P<0.05$ vs controls, ${ }^{\#} P<0.05$ for GBP vs DS. 


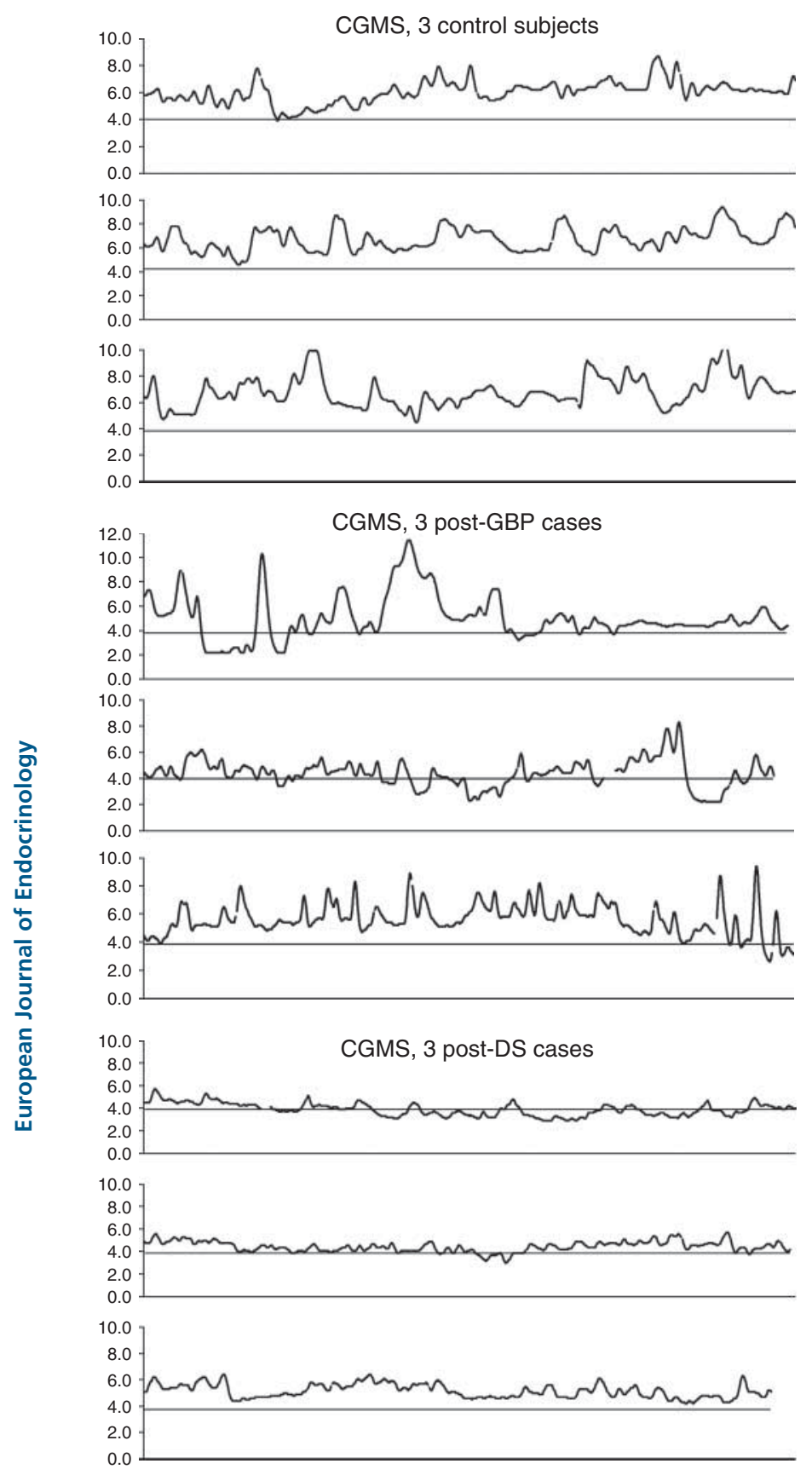

\section{Figure 2}

Examples of typical CGM curves, three per group. Note the high variability in the GBP group in contrast to the low variability in the DS group.

\section{Food diary}

The post-surgery patients consumed more frequent meals during the day than the controls did, as might be expected considering the postoperative food recommendations of
7.5 and 7.3 meals/day for GBP and DS, respectively, as compared to 6.0 meals/day for controls. The difference in the frequency of meals between patients with and without hypoglycemia was not significant or correlated to the number of hypoglycemic episodes.

\section{Discussion}

These results indicate that GBP patients have high glucose variability with frequent hypoglycemia (2.9\%) when compared to controls, whereas DS patients have low glucose variability but twice as frequent hypoglycemias (5.9\%). Because CONGA scores between 0.4 and 1.5 have been reported in healthy individuals (36), the present score of 2.1 in the GBP group illustrates that the variability is indeed high.

The DS group, on the other hand, exhibited the lowest variability, with low MAGE and CONGA values, and they had the lowest mean glucose levels as well as both the lowest mean peak and minimum values as compared to the other groups. They also demonstrated the lowest insulin, HbA1c, and HOMA-IR levels in the present study, all of which were in line with low and stable glucose curves. This was also in accordance with the very high frequency of diabetes remission reported for post-DS surgery (98\%) (1). Furthermore, the difference between fasting glucose and nadir glucose during CGM did not differ between any of the groups, which indicates that the variability downward from fasting glucose does not change following any of the surgeries. Rather, it is mainly the fasting glucose set point that changes post-surgery. The reason for the considerable difference between the two surgical procedures might be the great difference in the location where glucose is first presented and absorbed in the small intestine (i.e., in the proximal jejunum in the GBP patients and in the distal ileum, $\sim 250 \mathrm{~cm}$ from the ileocecal valve, in the DS method). Following both surgeries, the saccharides are degraded much later than normal by the pancreatic amylase, and for the DS group, the degrading effect of the intestinal disaccharidases and oligosaccharidases, which occur in declining concentrations down the small intestine, is greatly diminished. This in turn renders saccharide breakdown and absorption highly ineffective. In addition, DS patients are capable of eating larger portions than GBP patients are. The differences in the degradation and absorption of nutrients and in portion sizes probably have a bearing on the strikingly different glucose curves post-surgery. The frequency of meals does not seem to be related to problems of hypoglycemia, seeing as it did not differ 
Table 3 Continuous glucose monitoring characterizing glucose levels and hypoglycemic episodes. Means (s.E.M.; range); $3.3 \mathrm{mmol} / \mathrm{l}=60 \mathrm{mg} / \mathrm{dl} ; 2.8 \mathrm{mmol} / \mathrm{l}=50 \mathrm{mg} / \mathrm{dl}$. $\Delta$ Glucose, fasting glucose-nadir (CGM) glucose; hypoglycemic episodes with symptoms, percentage of all hypoglycemic episodes that were accompanied with symptoms.

\begin{tabular}{l}
\hline \\
\hline Average glucose $(\mathrm{mmol} / \mathrm{l})$ \\
Peak glucose $(\mathrm{mmol} / \mathrm{l})$ \\
Minimum glucose $(\mathrm{mmol} / \mathrm{l})$ \\
$\Delta \mathrm{Glucose}$ \\
Min/day $<3.3 \mathrm{mmol} / \mathrm{l}$ \\
Min/day $<2.8 \mathrm{mmol} / \mathrm{l}$ \\
No. of postprandial hypoglycemias $/ 24 \mathrm{~h}$ \\
Hypoglycemic episodes with symptoms \\
Meals/day
\end{tabular}

\begin{tabular}{c} 
GBP $(n=15)$ \\
\hline $5.9(0.3 ; 4.4-8.8)^{\dagger}$ \\
$10.5(0.5 ; 7.8-13.9)^{\dagger}$ \\
$3.3(0.3 ;<2.2-5.6)^{*}$ \\
$2.0(0.3 ; 0.4-3.6)$ \\
$42(15 ; 0-200)^{*}$ \\
$21(11 ; 0-127)^{*}$ \\
$0.6(0.2 ; 0-2)^{*}$ \\
$22 \% *$ \\
$7.5(0.5 ; 4.0-13.0)^{*}$
\end{tabular}

\begin{tabular}{c}
\hline DS $(n=15)$ \\
\hline $4.8(0.2 ; 3.9-6.0)^{*}$ \\
$7.1(0.3 ; 5.7-9.5)^{*}$ \\
$3.1(0.2 ;<2.2-4.2)^{*}$ \\
$1.5(0.2 ;-0.2$ to 3.0$)$ \\
$85(46 ; 0-675)^{*}$ \\
$39(31 ; 0-478)^{*}$ \\
$1.0(0.3 ; 0-3.7)^{*}$ \\
$20 \% *$ \\
$7.3(0.5 ; 4.0-12.3)^{*}$ \\
\hline
\end{tabular}

\begin{tabular}{c}
\hline Control $(n=15)$ \\
\hline $6.2(0.3 ; 5.1-9.2)$ \\
$9.1(0.5 ; 7.0-10.3)$ \\
$4.1(0.1 ; 3.3-5.6)$ \\
$1.8(0.2 ; 0.5-3.1)$ \\
$0(0)$ \\
$0(0)$ \\
0 \\
0 \\
$6.0(0.3 ; 3.7-8.7)$ \\
\hline
\end{tabular}

$* P<0.05$ vs controls and ${ }^{\dagger} P<0.05$ for GBP vs DS.

between patients with and without hypoglycemia. The post-surgery groups had similar present BMIs, but they differed in preoperative BMIs and post-surgery BMI loss, all of which in accordance with the initial selection of patients, as mentioned earlier in the present report. The superior weight loss noted here after DS is well in line with comparative studies (2), and it makes the pre-surgical difference inevitable, because we believe that it was most important to have weight-stable subjects with equivalent BMIs at the time of the study.

The common problem of false low glucose values with CGM, especially during the nighttime, seems to have been eliminated with the new generation of CGMs, which are equipped with better technology and improved algorithms (in the present case, Medtronic IPRO-2), seeing as the control group had no low glucose values $(<3.3 \mathrm{mmol} / \mathrm{l}$, or $<60 \mathrm{mg} / \mathrm{dl})$ at all. Even though CGM in general tends to slightly underestimate glucose levels and to present glucose levels with a little lag as compared to plasma levels (39), low levels $(<3.3 \mathrm{mmol} / \mathrm{l}$, or $<60 \mathrm{mg} / \mathrm{dl}$ ) are very uncommon. For example, when examining 74 healthy non-diabetic individuals for 3-7 days, only $0.2 \%$ of the time ( $2.9 \mathrm{~min} /$ day) was spent in hypoglycemia (40). The time lag between plasma and interstitial fluid glucose has been shown to be $4-8 \mathrm{~min}(41,42)$, and the IG level in men is believed to not decrease before a plasma glucose decrease in hypoglycemia (43). The potential problem with calibrating the sensor can in fact instead lead to an underestimation of the number of hypoglycemias (42).

Strictly defining hypoglycemia is not easily done. Clinically, Whipple's triad, which includes symptoms of hypoglycemia, low plasma glucose, and regression of symptoms when plasma glucose levels are raised, has been used. Most studies use $3.3 \mathrm{mmol} / \mathrm{l}(60 \mathrm{mg} / \mathrm{dl})$ as the lower limit, but $2.8 \mathrm{mmol} / \mathrm{l}(50 \mathrm{mg} / \mathrm{dl})$ and $3.9 \mathrm{mmol} / \mathrm{l}$ $(70 \mathrm{mg} / \mathrm{dl})$ are also frequently used in reports. The American Diabetes Association defines hypoglycemia as $<3.9 \mathrm{mmol} / \mathrm{l}$ plasma glucose, with or without symptoms (44). In healthy subjects, the counter-regulatory hormones glucagon, GH, epinephrine, and norepinephrine are secreted when glucose reaches $3.6-3.8 \mathrm{mmol} / \mathrm{l}$ $(65-68 \mathrm{mg} / \mathrm{dl})$. Autonomic symptoms begin at $3.2 \mathrm{mmol} / \mathrm{l}$ $(58 \mathrm{mg} / \mathrm{dl})$, whereas neuroglycopenic symptoms and deterioration in cognitive function tests begin at $2.8 \mathrm{mmol} / \mathrm{l}(51 \mathrm{mg} / \mathrm{dl})$ (45). Cortisol is secreted at $3.2 \mathrm{mmol} / \mathrm{l}(58 \mathrm{mg} / \mathrm{dl})$ in healthy subjects (46).

The side effects of hypoglycemia are abundant and often severe; hypoglycemia has been shown to severely impair cognitive executive functions in both diabetic and healthy controls when tested with hyperinsulinemic hypoglycemic clamps (47). In 22 healthy volunteers, seven out of 12 cognitive tests were abnormal at $2.9 \mathrm{mmol} / \mathrm{l}$ glucose, and all of the tests were abnormal at $2.5 \mathrm{mmol} / \mathrm{l}$ glucose (48). It is well known that in insulintreated patients, daily hypoglycemia (49) and asymptomatic nocturnal hypoglycemia lowers the glucose level, thereby triggering counter-regulatory hormone response and symptoms, and it actually preserves cognitive function during subsequent hypoglycemia $(50,51)$. When testing for symptoms and cognitive function in healthy subjects over 4 consecutive days, the threshold for symptoms with cognitive impairment on day 1 was $3.6 \mathrm{mmol} / \mathrm{l}$, but it decreased to $2.5 \mathrm{mmol} / \mathrm{l}$ on day 4 (52).

It has been shown that both acute and chronic (both insulin-induced and fast-induced) hypoglycemia up-regulates genes for glucose uptake (GLUT1, AGT, ID1, and $M K P$ ) in the hypothalamus, thereby preserving the brain's need for glucose, and it also down-regulates the counterregulatory response $(53,54)$. This phenomenon could be 
Table 4 Episodes in min of hypoglycemia ( $<3.3 \mathrm{mmol} / \mathrm{l}$, or $<60 \mathrm{mg} / \mathrm{dl}$, glucose) recorded in GBP and DS patients by CGM over 3 days. Episodes associated with subjective symptoms are given in bold text. Two episodes $(*)$ occurred in a fasting state. One patient (no. 6) reported hypoglycemic symptoms on three occasions but the CGM did not detect any low glucose values.

\begin{tabular}{|c|c|c|}
\hline Cases & Daytime 0800-2400 h & Night time $2400-0800 \mathrm{~h}$ \\
\hline \multicolumn{3}{|l|}{ GBP } \\
\hline 1 & 0 & 65,55 \\
\hline 2 & 80,50 & 300 \\
\hline 3 & $20,15,15,15$ & 55 \\
\hline 4 & $100,50,40$ & $235,150,25$ \\
\hline 5 & 0 & 0 \\
\hline 6 & 0 & 0 \\
\hline 7 & $115,15,15$ & 0 \\
\hline 8 & $90,30,25$ & 0 \\
\hline 9 & 0 & 0 \\
\hline 10 & $65,50,40$ & 0 \\
\hline 11 & 0 & 0 \\
\hline 12 & 0 & 0 \\
\hline 13 & 0 & 0 \\
\hline 14 & 50 & $105 *$ \\
\hline 15 & 0 & 0 \\
\hline \multicolumn{3}{|l|}{ DS } \\
\hline 16 & 0 & 25,15 \\
\hline 17 & $50,20,20$ & 25,15 \\
\hline 18 & 0 & $45,60,120 *, 150$ \\
\hline 19 & $50,55,115,195$ & $115,120,125$ \\
\hline 20 & 0 & 0 \\
\hline 21 & $\begin{array}{l}45,50,60,90,150,170 \\
\quad 180,240\end{array}$ & $60,480,500$ \\
\hline 22 & 0 & 30 \\
\hline 23 & 0 & 15,60 \\
\hline 24 & $10,10,25$ & 15 \\
\hline 25 & $5,5,20$ & 0 \\
\hline 26 & 0 & 0 \\
\hline 27 & 0 & 5,5 \\
\hline 28 & 0 & 0 \\
\hline 29 & 20,175 & 20,50 \\
\hline 30 & 0 & 0 \\
\hline
\end{tabular}

part of the explanation for the large number of asymptomatic hypoglycemias. The fact that the patients were aware of only about one-fifth of all hypoglycemic episodes might indicate that the patients in the two surgical groups had adapted to their new metabolic status. However, the consequence of hypoglycemia unawareness on quality of life and cognition remains to be clarified in these expanding groups of patients.

With regards to the basal characteristics of the three study groups, there were several differences (see Table 2). In particular, the DS patients had lower glucose, HbA1c, and insulin values and higher adiponectin, a parameter profile that suggests increased insulin sensitivity. The morning values of ketones (3- $\beta$-hydroxybuturate) and free fatty acids were not elevated. The DS group showed lower levels of free fatty acids than the control group did, which in accordance with previous studies $(21,55)$. This might reflect the supranormal high insulin sensitivity of this group with marked anti-lipolysis in spite of low levels of insulin (56). Direct studies of lipid turnover could clarify this aspect.

These findings implicate that the regular GBP/DS patient has a high likelihood of having either symptomatic or non-symptomatic frequent hypoglycemia, and symptoms and signs of these conditions could be sought at consultation. If episodes of hypoglycemia are suspected, CGM could be performed to evaluate the existence of such episodes.

In conclusion, hypoglycemic episodes after bariatric surgery seem to occur more frequently than was previously acknowledged; we noted that the mean time spent in the hypoglycemic state (of $<3.3 \mathrm{mmol} / \mathrm{l}$, or $60 \mathrm{mg} / \mathrm{dl}$, glucose) was $42 \mathrm{~min} / 24 \mathrm{~h}$ (2.9\%) for GBP patients and $85 \mathrm{~min} / 24 \mathrm{~h}$ (5.9\%) for DS patients. Healthy individuals have been reported to spend $2.9 \mathrm{~min} / 24 \mathrm{~h}(0.2 \%)$ in hypoglycemia (19); however, in the present study, controls spent no time at all in hypoglycemia. To our knowledge, hypoglycemia to this extent has not been reported in DS patients, who are generally considered to have superior glucose levels post-surgery. Future studies that examine the counter-regulatory response of postbariatric patients, their adaptation to hypoglycemia, and the impact of hypoglycemia on quality of life and cognitive function are warranted.

Declaration of interest

The authors declare that there is no conflict of interest that could be perceived as prejudicing the impartiality of the research reported.

\section{Funding}

This work was funded by Uppsala University. Medtronic funded the CGM equipment, and Bayer funded the glucose meters.

Author contribution statement

All of the authors designed the project and wrote and revised the manuscript. N Abrahamsson conducted the experiment and analyzed the data. F A Karlsson is the guarantor of this work.

\section{Acknowledgements}

We are very grateful to Medtronic for the use of the IPRO-2 CGM and to Bayer for the use of the CONTOUR glucose meter. We thank study nurses Maria Forsberg and Elisabeth Olsson for their valuable assistance. 


\section{References}

1 Buchwald H, Avidor Y, Braunwald E, Jensen MD, Pories W, Fahrbach K \& Schoelles K. Bari-atric surgery: a systematic review and meta-analysis. Journal of the American Medical Association 2004292 1724-1737. (doi:10.1001/jama.292.14.1724)

2 Hedberg J \& Sundbom M. Superior weight loss and lower HbA1c 3 years after duodenal switch compared with Roux-en-Y gastric bypass - a randomized controlled trial. Surgery for Obesity and Related Diseases 2012 8 338-345. (doi:10.1016/j.soard.2012.01.014)

3 Patti ME \& Goldfine AB. Hypoglycemia after GBP: the dark side of GLP-1. Gastroenterology 2014146 605-608. (doi:10.1053/j.gastro.2014. 01.038)

4 Goldfine AB, Mun EC, Devine E, Bernier R, Baz-Hecht M, Jones DB, Schneider BE, Holst JJ \& Patti ME. Patients with neuroglycopenia after GBP Surgery have exaggerated incretin and insulin secretory responses to a mixed meal. Journal of Clinical Endocrinology and Metabolism 2007 92 4678-4685. (doi:10.1210/jc.2007-0918)

5 Marsk R, Jonas E, Rasmussen F \& Näslund E. Nationwide cohort study of post-gastric bypass hypoglycaemia including 5,040 patients undergoing surgery for obesity in 1986-2006 in Sweden. Diabetologia 201053 2307-2311. (doi:10.1007/s00125-010-1798-5)

6 Patti ME, McMahon G, Mun EC, Bitton A, Holst JJ, Goldsmith J, Hanto DW, Callery M, Arky R, Nose V et al. Servere hypoglycemia post-gastric bypass requiring partial pancreatectomy: evidence for inappropriate insulin secretion and pancreatic islet hyperplasia. Diabetologia 200548 2236-2240. (doi:10.1007/s00125-005-1933-x)

7 Lee CJ, Brown T, Magnuson TH, Egan JM, Carlson O \& Elahi D. Hormonal response to a mixed-meal challenge after reversal of GBP for hypoglycemia. Journal of Clinical Endocrinology and Metabolism 201398 E1208-E1212. (doi:10.1210/jc.2013-1151)

8 Service GJ, Thompson GB, Service FJ, Andrews JC, Collazo-Clavell ML \& Lloyd RV. Hyperinsulinemic hypoglycemia with nesidioblastosis after GBP surgery. New England Journal of Medicine 2005353 249-254. (doi:10.1056/NEJMoa043690)

9 Meier JJ, Butler AE, Galasso R \& Butler PC. Hyperinsulinemic hypoglycemia after GBP surgery is not accompanied by islet hyperplasia or increased ( $\beta$ )-cell turnover. Diabetes Care 200629 1554-1559. (doi:10.2337/dc06-0392)

10 Reubi JC, Perren A, Rehmann R, Waser B, Christ E, Callery M, Goldfine AB \& Patti ME. Glukagon-like peptide-1 (GLP-1) receptors are not overexpressed in pancreatic islets from patients with severe hyperinsulinemic hypoglycemia following GBP. Diabetologia 201053 2641-2645. (doi:10.1007/s00125-010-1901-y)

11 Salehi M, Prigeon RL \& D'Alessio DA. GBP surgery enhances GLP-1-stimulated postprandial insulin secretion in humans. Diabetes 201160 2308-2314. (doi:10.2337/db11-0203)

12 Salehi M, Gastadelli A \& D'Alessio DA. Blockade of GLP-1 receptor corrects postprandial hypoglycemia after GBP. Gastroenterology 2014 146 669-680. (doi:10.1053/j.gastro.2013.11.044)

13 Action to Control Cardiovascular Risk in Diabetes Study Group , Gerstein HC, Miller ME, Byington RP, Goff DC, Bigger JT, Buse JB, Cushman WC, Genuth S \& Ismail-Beigi F. Effects of intensive glucose lowering in type 2 diabetes. New England Journal of Medicine 2008358 2545-2559. (doi:10.1056/NEJMoa0802743)

14 Whitmer RA, Karter AJ, Yaffe K, Quesenberry CP \& Selby JV. Hypoglycemic episodes and risk of dementia in older patients with type 2 diabetes mellitus. Journal of the American Medical Association 2009301 1565-1572. (doi:10.1001/jama.2009.460)

15 Davis RE, Morrissey M, Peters JR, Wittrup-Jensen K, Kennedy-Martin T $\&$ Currie CJ. Impact of hypoglycaemia on quality of life and productivity in type 1 and type 2 diabetes. Current Medical Research and Opinion 200521 1477-1483. (doi:10.1185/030079905X61929)

16 Redelmeier DA, Kenshole AB \& Ray JG. Motor vehicle crashes in diabetic patients with tight glycemic control: a population-based case
Control analysis. PLoS Medicine 20096 e1000192. (doi:10.1371/journal. pmed.1000192)

17 Adams TD, Gress RE, Smith SC, Halverson RC, Simper SC, Rosamond WD, Lamonte MJ, Stroup AM \& Hunt SC. Long-term mortality after gastric bypass surgery. New England Journal of Medicine 2007357 753-761. (doi:10.1056/NEJMoa066603)

18 Ritz P, Vaurs C, Bertrand M, Anduze Y, Guillame E \& Hanaire H. Usefullness of acarbose and dietary modifications to limit glycemic variability following Roux-en-Y gastric bypass as assessed by continuous monitoring. Diabetes Technology \& Therapeutics 201214 736-740. (doi:10.1089/dia.2011.0302)

19 Hanaire H, Bertrand M, Guerzi B, Anduze Y, Guillame E \& Ritz P. High glycemic variability assessed by continuous glucose monitoring after surgical treatment of obesity by gastric bypass. Diabetes Technology \& Therapeutics 201113 625-630. (doi:10.1089/dia.2010.0203)

20 Halperin F, Patti ME, Skow M, Bajwa M \& Goldfine AB. Continuous glucose monitoring for evaluation of glycemic excursions after gastric bypass. Journal of Obesity 20112011 869536. (doi:10.1155/2011/869536)

21 Johansson HE, Haenni A, Karlsson FA, Edén-Engström B, Ohrvall M, Sundbom M \& Zethelius B. Bileopancreatic diversion with duodenal switch lowers both early and late phases of glucose, insulin and proinsulin responses after meal. Obesity Surgery 201020 549-558. (doi:10.1007/s11695-010-0102-6)

22 Roslin MS, Dudiy Y, Brownlee A, Weiskopf J \& Shah P. Response to glucose tolerance testing and solid high carbohydrate challenge: comparison between Roux-en-Y gastric bypass, vertical sleeve gastrectomy, and duodenal switch. Surgical Endoscopy 201428 91-99. (doi:10.1007/s00464-013-3176-0)

23 Camastra S, Manco M, Mari A, Baldi S, Gastaldelli A, Greco AV, Mingrone $G \&$ Ferrannini E. $\beta$-cell function in morbidly obese subjects during free living. Diabetes $2005 \mathbf{5 4}$ 2382-2389. (doi:10.2337/diabetes. 54.8.2382)

24 Nadelson J \& Epstein A. A rare case of noninsulinoma pancreatogenous hypoglycemia syndrome. Gastrointestinal Medicine 20122012164305. (doi:10.1155/2012/164305)

25 Valderas JP, Ahuad J, Rubio L, Escalona M, Pollak F \& Maiz A. Acarbose improves hypoglycaemia following gastric bypas surgery without increasing glucagon-like peptide 1 level. Obesity Surgery 201222 582-586. (doi:10.1007/s11695-011-0581-0)

26 Moreira RO, Moreira RB, Machado NA, Gonçalves TB \& Coutinho WF. Post-prandial hypoglycemia after bariatric surgery: pharmacological treatment with verapamil and acarbose. Obesity Surgery 200818 1618-1621. (doi:10.1007/s11695-008-9569-9)

27 Myint KS, Greenfield JR, Farooqi IS, Henning E, Holst JJ \& Finer N. Prolonged successful therapy for hyperinsulinemic hypoglycemia after gastric bypass: the pathophysiological role of GLP-1 and its response to a somatostatin analogue. European Journal of Endocrinology 2012166 951-955. (doi:10.1530/EJE-11-1065)

28 de Heide LJ, Laskewitz AJ \& Apers JA. Treatment of severe postRGBP hyperinsulinemic hypoglycemia with pasireotide: a comparison with octreotide on insulin, glucagon, and GLP-1. Surgery for Obesity and Related Diseases 201410 e31-e33. (doi:10.1016/j.soard.2013.11.006)

29 Gonzalez-Gonzalez A, Delgado M \& Fraga-Fuentes MD. Use of diazoxide in management of severe postprandial hypoglycemia in patient after Roux-en-Y gastric bypass. Surgery for Obesity and Related Diseases 20139 e18-e19. (doi:10.1016/j.soard.2011.05.010)

30 Yunfeng C \& Elahi A. Advances in the etiology and management of hyperinsulinemic hypoglycemia after Roux-en-Y gastric bypass. Journal of Gastrointestinal Surgery 201115 1879-1888. (doi:10.1007/ s11605-011-1585-8)

31 Halperin F, Patti ME \& Goldfine AB. Glucagon treatment for post-gastric bypass hypoglycemia. Obesity 201018 1858-1860. (doi:10.1038/oby.2010.15)

32 Abrahamsson N, Eden Engström B, Sundbom M \& Karlsson FA. GLP1 analogs as treatment of postprandial hypoglycemia following gastric 
bypass surgery: a potential new indication? European Journal of Endocrinology 2013169 885-889. (doi:10.1530/EJE-13-0504)

33 Monnier L \& Colette C. Target for glycemic control. Diabetes Care 2009 32 S199-S204. (doi:10.2337/dc09-S310)

34 McAulay V, Deary IJ \& Frier BM. Symptoms of hypoglycemia in people with diabetes. Diabetic Medicine 200118 690-705. (doi:10.1046/ j.1464-5491.2001.00620.x)

35 Matthews DR, Hosker JP, Rudenski AS, Naylor BA, Treacher DF \& Turner RC. Homeostasis model assessment: insulin resistance and $\beta$-cell function from fasting plasma glucose and insulin concentrations in man. Diabetologia 198528 412-419. (doi:10.1007/ BF00280883)

36 McDonell CM, Donath SM, Vidmar SI, Werther GA \& Cameron FJ. A novel approach to continouos glucose analysis utilizing glycemic variation. Diabetes Technology \& Therapeutics 20057 253-263. (doi:10.1089/dia.2005.7.253)

37 Cameron FJ, Donath SM \& Baghurst PA. Measuring glycemic variation. Current Diabetes Reviews 20106 17-26. (doi:10.2174/157339910790 442592)

38 Service FJ, Molnar GD, Rosevear JW, Ackerman E, Gatewood LC \& Taylor WF. Mean amplitude of glycemic excursions, a measure of diabetic instability. Diabetes 197019 644-655. (doi:10.2337/ diab.19.9.644)

39 Baek YH, Jin HY, Lee KA, Kang SM, Kim WJ, Kim MG, Park JH, Chae SW, Baek HS \& Park TS. The correlation and accuracy of glucose levels between interstitial fluid and venous plasma by continuous glucose monitoring system. Korean Diabetes Journal 201034 350-358. (doi:10.4093/kdj.2010.34.6.350)

40 Juvenile Diabetes Research Foundation Continouos Glucose Monitoring Study Group , Fox LA, Beck RW \& Xing D. Variation of interstitial glucose measurements assessed by continuous glucose monitors in healthy, nondiabetic individuals. Diabetes Care 201033 1297-1299. (doi:10.2337/dc09-1971)

41 Steil GM, Rebrin K, Mastrototaro J, Bernaba B \& Saad MF. Determination of plasma glucose during rapid glucose excursions with a subcutaneous glucose sensor. Diabetes Technology \& Therapeutics 20035 27-31. (doi:10.1089/152091503763816436)

42 Steil GM, Rebrin K, Harari F, Jinagonda S, Tadros S, Darwin C \& Saad MF. Interstitial fluid glucose dynamics during insulin-induced hypoglycemia. Diabetologia 200548 1833-1840. (doi:10.1007/ s00125-005-1852-x)

43 Boyne MS, Silver DM, Kaplan J \& Saudek CD. Timing of changes in interstitial and venous blood glucose measured with a continuous subcutaneous glucose sensor. Diabetes 200352 2790-2794. (doi:10.2337/diabetes.52.11.2790)

44 Workgroup on Hypoglycemia, American Diabetes Association. Defining and reporting hypoglycemia in diabetes: a report from the American Diabetes Association Workgroup on Hypoglycemia. Diabetes Care 200528 1245-1249. (doi:10.2337/diacare.28.5.1245)
45 Mitrakou A, Ryan C, Veneman T, Mokan M, Jenssen T, Kiss I, Durrant J, Cryer P \& Gerich J. Hierarchy of glycemic thresholds for counterregulatory hormone secretion, symptoms, and cerebral dysfunction. American Journal of Physiology 1991260 E67-E74.

46 Schwartz NS, Clutter WE, Shah SD \& Cryer PE. Glycemic thresholds for activation of glucose counterregulatory systems are higher than the threshold for symptoms. Journal of Clinical Investigation $1987 \mathbf{7 9}$ 777-781. (doi:10.1172/JCI112884)

47 Graveling AJ, Deary IJ \& Frier BM. Acute hypoglycemia impairs executive cognitive function in adults with and without type 1 diabetes. Diabetes Care 201336 3240-3246. (doi:10.2337/dc13-0194)

48 Fanelli C, Pampanelli S, Epifano L, Rambotti AM, Ciofetta M, Modarelli F, Di Vincenz A, Annibale B, Lepore M, Lalli C et al. Relative roles of insulin and hypoglycaemia on induction of neuroendocrine responses to, symptoms of, and deterioration of cognitive function in hypoglycaemia in male and female humans. Diabetologia 199437 797-807. (doi:10.1007/BF00404337)

49 Heller SR \& Cryer PE. Reduced neuroendocrine and symptomatic responses to sub-sequent hypoglycemia after 1 episode of hypoglycemia in nondiabetic humans. Diabetes 199140 223-226. (doi:10.2337/ diab.40.2.223)

50 Veneman T, Mitrakou A, Mokan M, Cryer P \& Gerich J. Induction of hypoglycemia unawareness by asymptomatic nocturnal hypoglycemia. Diabetes 199342 1233-1237. (doi:10.2337/diab.42.9.1233)

51 Fanelli CG, Paramore DS, Hershey T, Terkamp C, Ovalle F, Craft S \& Cryer PE. Impact of nocturnal hypoglycemia on hypoglycemic cognitive dysfunction in type 1 diabetes. Diabetes 199847 1920-1927. (doi:10.2337/diabetes.47.12.1920)

52 Boyle PJ, Nagy RJ, O'Connor AM, Kempers SF, Yeo RA \& Qualls C. Adaptation in brain glucose uptake following recurrent hypoglycemia. PNAS 199491 9352-9356. (doi:10.1073/pnas.91.20.9352)

53 Simpson IA, Appel NM, Hokari M, Oki J, Holman GD, Maher F, Koehler-Stec EM, Vannucci SJ \& Smith QR. Blood-brain barrier glucose transporter effects of hypo- and hyperglycemia revisited. Journal of Neurochemistry 199972 238-247. (doi:10.1046/j.1471-4159.1999. 0720238.x)

54 Mastaitis JW, Wurmbach E, Cheng H, Sealfon SC \& Mobbs CV. Acute induction of gene expression in brain and liver by insulininduced hypoglycemia. Diabetes 200554 952-958. (doi:10.2337/ diabetes.54.4.952)

55 Mari A, Manco M, Guidone C, Nanni G, Castagneto M, Mingrone G \& Ferrannini E. Restoration of normal glucose tolerance in severely obese patients after bilio-pancreatic diversion: role of insulin sensitivity and $\beta$ cell function. Diabetologia 200649 2136-2143. (doi:10.1007/s00125006-0337-x)

56 Camastra S, Manco M, Mari A, Baldi S, Gastaldelli A, Greco AV, Mingrone $\mathrm{G} \&$ Ferrannini E. $\beta$-cell function in morbidly obese subjects during free living: long-term effects of weight loss. Diabetes $2005 \mathbf{5 4}$ 2382-2389. (doi:10.2337/diabetes.54.8.2382)

Received 29 September 2014

Revised version received 20 April 2015

Accepted 21 April 2015 